\title{
Acute effects of ozone on pulmonary function of cyclists receiving antioxidant supplements
}

\author{
Linda Grievink, Saskia M A Jansen, Pieter van't Veer, Bert Brunekreef
}

\begin{abstract}
Objectives-To identify whether acute lung function effects of ozone can be modulated by antioxidant vitamin supplementation.

Methods-Amateur cyclists $(n=26)$ were studied in the summer of 1994 in The Netherlands. Repeated lung function measurements were performed with a rolling seal spirometer after training sessions or competitive races on four to 14 occasions. The cyclists were assigned to two study groups. The supplementation group $(n=12)$ received antioxidant supplements (15 mg $\beta$-carotene, $75 \mathrm{mg}$ vitamin $E$, and $650 \mathrm{mg}$ vitamin $\mathrm{C}$ ) once a day for three months. The control group did not receive supplementation. For each subject, lung function after exercise was regressed on the previous eight hour mean ozone concentration. The individual regression coefficients were pooled for each study group and weighted with the inverse of the variance.

Results-The eight hour mean ozone concentration was $101 \mu \mathrm{g} / \mathrm{m}^{3}$ (30 to $205 \mu \mathrm{g} / \mathrm{m}^{3}$ ). For the supplementation group, there was no effect of ozone on FVC, $\mathrm{FEV}_{1}$, peak expiratory flow (PEF), and maximal midexpiratory flow (MMEF). For the control group the mean coefficients were negative, except for MMEF. The difference between the groups was 2.08 (95\% confidence interval $(95 \% \mathrm{CI}) 1.31$ to 2.85$)$ $\mathrm{m} 1 / \mu \mathrm{g} / \mathrm{m}^{3}$ for FVC, $1.66(95 \%$ CI 0.62 to 2.70) for $\mathrm{FEV}_{1}, 6.83$ (95\% CI 3.17 to 10.49$)$ for PEF, and $0.42(95 \% \mathrm{CI}-1.38$ to 2.22$)$ for MMEF.

Conclusion-The results suggest that antioxidant vitamin supplementation protects against acute effects of ozone on lung function in heavily exercising amateur cyclists.
\end{abstract}

(Occup Environ Med 1998;55:13-17)

Keywords: ozone; lung function; antioxidants

Netherlands Institute of Health Sciences (NIHES)

L Grievink

Correspondence to: Linda Grievink, Department of Environmental Sciences, Occupational and Environmental Health Group, Wageningen Agricultural University, $\mathrm{PO}$ Box 238, $6700 \mathrm{AE}$ Wageningen,

The Netherlands.

Accepted 10 July 1997 toms increased. ${ }^{4}$ Low levels of ambient ozone on respiratory effects have been studied before in amateur cyclists. The difference between lung function before and after exercise was negatively related to ozone concentrations during exercise. Shortness of breath, chest tightness, and wheeze were increased after exposure to ozone. ${ }^{6}$

A possible mechanism for decrements in lung function after exposure to ozone is its oxidant role, inducing direct and indirect injury to lung tissues by attracting inflammatory cells. Antioxidants such as provitamin $\beta$-carotene and vitamins $\mathrm{E}$ and $\mathrm{C}$, can possibly modulate the reactivity of oxidants by reacting with them before they injure the lung tissue. ${ }^{7}$ Few laboratory studies have investigated this hypothesis, suggesting a protective role for vitamin $\mathrm{C}$ and a combination of vitamins $\mathrm{C}$ and $\mathrm{E},{ }^{8}$ but not for vitamin $\mathrm{E}$ alone. ${ }^{9}$

As all studies were performed under laboratory conditions, it is unknown whether antioxidants can play a part in the respiratory health effects of ambient ozone in healthy adults. We explored this hypothesis in a small study measuring lung function among amateur cyclists with and without supplementation of antioxidants during summer.

\section{Methods}

STUDY DESIGN

Two amateur cycling clubs in Ede and Arnhem, both located in the east of The Netherlands, were asked to participate in the study. From 28 June until 1 September 1994 lung function was measured in each subject before and after each training session or competitive race on several occasions. All training sessions and races took place in rural areas. There were no large industrial areas or cities in the surroundings. Ozone concentration data were obtained from the nearest station (Wageningen, Loenen) measured by the national air quality monitoring network operated by the National Institute of Public Health and the Environment (RIVM) in Bilthoven. Training sessions and races took place in the late afternoon and early evening when ozone concentrations tend to peak. The exact times were recorded for each participant to calculate the individual exposure to ozone (eight hour mean ozone concentration before the end of exercise) and to calculate the duration of exercise. Meteorological data were obtained from the nearest station (Deelen) operated by the Royal Netherlands Meteorological Institute (KNMI) at the Bilt.

\section{STUDY POPULATION}

From 29 volunteers, 23 subjects were randomly assigned to the supplementation or control group. Five subjects were directly allocated 
to the control group, as they refused to take any supplementation or entered the study half way through. One subject who regularly took vitamin and mineral supplements and refused to stop was allocated to the supplementation group. At the beginning of the study, subjects completed a questionnaire about chronic respiratory symptoms and other relevant characteristics.

\section{SUPPLEMENTATION}

The supplementation group received $650 \mathrm{mg}$ vitamin $\mathrm{C}, 75 \mathrm{mg}$ vitamin $\mathrm{E}$, and $15 \mathrm{mg}$ of $\beta$-carotene daily starting one week before the measurements started for 70 days (JuneSeptember). This supplementation was commercially available in two different pills. The control group did not receive a placebo. Before and after supplementation plasma was collected as a marker of compliance.

\section{MEASUREMENTS}

Blood specimens were collected in ethylene diamine tetra-acetic acid (EDTA) vacutainer tubes, stored in a box on ice, and centrifuged within five hours to obtain plasma. Aliquots were then stored at $-80^{\circ} \mathrm{C}$ until analyses. Concentrations of $\alpha$-tocopherol and $\beta$-carotene were measured by high performance liquid chromatography (HPLC) together in one run. The column was a prepackaged $25 \mathrm{~cm} \times 4.6$ $\mathrm{mm}$ Vydac 201TP54, $\mathrm{C}_{18} 300 \AA$ (Hesperia, CA, USA). Detection after separation was performed by two ultraviolet (UV) detectors, one for determination of retinol and carotenoids (UV2000) at wave lengths of 325, 450, and 470 $\mathrm{nm}$. The second detector (UV1000) was used for determination of the tocopherols at wave lengths of $325 \mathrm{~nm}$ and $292 \mathrm{~nm}$.

For compliance with exertion, continuous heart rate was measured with Polar sport testers (Polar Electro, Finland). This was measured on several different occasions in all subjects during training and races. The volumes of inhaled air were estimated with heart rates in the equations of the study of Colucci. ${ }^{10}$

Lung function was measured before and after cycling with spirometry. All lung functions tests were conducted indoors at most 30 minutes before and 10 to 60 minutes after the exercise. Measurements were performed according to the ECCS guidelines. ${ }^{11}$ The subject was seated in an upright posture, with a fixed mouthpiece adjusted for height of each person and without a noseclip. For each measurement, subjects had to perform at least three technically acceptable and reproducible forced manoeuvres (according to ECCS 1983 criteria) with Vicatest 5 dry rolling seal spirometers. These spirometers were coupled to a microcomputer for storage of the data. Data handling was according to the ECCS guidelines. ${ }^{11}$ The spirometers had no internal temperature sensor; however, room temperature was recorded at all times. For logistic reasons, spirometers were brought into the rooms (local clubrooms with low ceilings) shortly before the preexercise measurement started. We therefore had no opportunity to control indoor conditions and high temperatures $\left(>30^{\circ} \mathrm{C}\right)$ that occurred regularly in these places. The air in the spirometer bell may not have adapted to the air temperature in the clubrooms on hot days when pre-exercise tests were performed, which may have resulted in an underestimation of the pre-exercise lung function. ${ }^{12}$ For this reason we focused the analyses on the postexercise lung function measurements which were conducted after the spirometers had been in the clubrooms for several hours.

\section{DATA ANALYSIS}

Before data analyses, the maximum value of three manoeuvres of each measurement was calculated for each subject for each of the following lung function variables: forced expiratory volume in one second $\left(\mathrm{FEV}_{1}\right)$, forced vital capacity (FVC), peak expiratory flow (PEF), and maximal mid-expiratory flow (MMEF). At the end of the study, a range of four to 14 observations was available for each subject - that is, lung function measurements after exercise. Subjects with a range in exposure to ozone of $<50 \mu \mathrm{g} / \mathrm{m}^{3} \quad(\mathrm{n}=3)$ were excluded from analyses because their estimated regression coefficients would be highly unstable. Individual regression analyses were performed in each subject with the SAS PROC REG procedure ${ }^{13}$ with a lung function variable after exercise $\left(\mathrm{FEV}_{1}, \mathrm{FVC}, \mathrm{PEF}\right.$, or $\left.\mathrm{MMEF}\right)$ as the dependent variable and with the previous eight hour mean ozone concentration as the independent variable. The resulting regression coefficients for each subject were pooled and group means (SEMs), medians, and means which were weighted with the inverse of the variance were calculated for the control and supplementation group. The effect of supplementation with a $95 \%$ confidence interval (95\% CI) was calculated as the difference between the mean regression coefficient of the supplementation and control group. Ambient temperature, $\mathrm{NO}_{2}$, and concentrations of particulate matter with mean diameter of 10 $\mu \mathrm{m}\left(\mathrm{PM}_{10}\right)$ were considered as confounding factors.

\section{Results}

A total of 26 respondents $(n=14$ in control group) contributed with 192 observations to the data analyses. The mean age of the respondents was 27.5 years and did not differ between the two study groups (table 1). Three participants were women. In the control group, one subject was a current smoker and two reported a pollen allergy diagnosed by a doctor. In the supplementation group more subjects reported having respiratory symptoms and allergy than in the control group. One subject reported having had attacks of chest tightness diagnosed by a doctor; another subject reported shortness of breath when walking at normal pace, and one subject reported coughing up phlegm almost every day for three months in the past two years. Two subjects reported an allergy to pets and house dust mites, and four others an allergy to pollen, all diagnosed by a doctor. Table 1 summarises means of number of observations, ozone concentration, duration of exercise, and heart 
Table 1 Mean and range in age, number of observations, ozone concentration, duration of exercise, and heart rate in the two study groups

\begin{tabular}{|c|c|c|c|c|}
\hline \multirow[b]{2}{*}{ Measurements } & \multicolumn{2}{|c|}{ Control group $(n=14)$} & \multicolumn{2}{|c|}{ Supplementation group $(n=12)$} \\
\hline & Mean & Range & Mean & Range \\
\hline $\operatorname{Age}^{\star}(\mathrm{y})$ & 28.5 & $20-41$ & 27.9 & $16-39$ \\
\hline Observations $\dagger(\mathrm{n})$ & 6.9 & $4-14$ & 7.9 & $5-12$ \\
\hline Ozone concentration $\ddagger\left(\mu \mathrm{g} / \mathrm{m}^{3}\right)$ & 97.9 & $30-205$ & 104.2 & 33-205 \\
\hline Duration of exercise (min) & 91.1 & $15-135$ & 92.7 & $15-135$ \\
\hline Heart rate (beats $/ \mathrm{min}$ ) & 154.0 & $132-180$ & 153.1 & $129-196$ \\
\hline
\end{tabular}

* Age of one subject from the control group is missing.

t Lung function measurement after exercise.

$\ddagger$ Eight hour mean ozone concentration.

Table $2 a$-Tocopherol and $\beta$-carotene concentrations ( $\mu$ mol/l) in plasma among control and supplementation group at baseline and the change during intervention

\begin{tabular}{|c|c|c|c|c|}
\hline & \multicolumn{2}{|c|}{ Control group $(n=9)$} & \multicolumn{2}{|c|}{ Supplementation group $(n=11)$} \\
\hline & $\begin{array}{l}\text { Baseline } \\
\text { mean (SEM) }\end{array}$ & $\begin{array}{l}\text { Change* } \\
\% \text { (range) }\end{array}$ & $\begin{array}{l}\text { Baseline } \\
\text { mean (SEM) }\end{array}$ & $\begin{array}{l}\text { Change* } \\
\% \text { (range) }\end{array}$ \\
\hline$\alpha$-Tocopherol & $23.0 \quad(7.66)$ & $9(-7-21)$ & $30.0 \quad(8.35)$ & $38(9-95)$ \\
\hline$\beta$-Carotene & $0.32(0.11)$ & $5(-19-26)$ & $0.50(0.14)$ & $153(10-345)$ \\
\hline
\end{tabular}

${ }^{\star}$ Mean individual change (after minus before divided by before intervention).

rate for the two study groups. The eight hour mean ozone concentration was $101 \mu \mathrm{g} / \mathrm{m}^{3}$ (range 30-205 $\mu \mathrm{g} / \mathrm{m}^{3}$ ), with no difference between the two groups. The figure shows the one hour maximum ozone concentrations for every day from June until August. Ozone concentrations were high from the end of June (at the start of the study) until the end of July, August had lower ozone concentrations. Eight hour mean temperature averaged $23^{\circ} \mathrm{C}$, with a range of $15-31^{\circ} \mathrm{C}$. The mean (range) duration of the exercise was not different between the two study groups (92 (15-135) minutes). Heart rate measurements were performed on 179 different occasions. During training sessions, mean (range) heart rate was 147 (129-190) bpm, and during competitive races, 165 (135-196) bpm. There was no difference between the groups. Estimated volumes of inhaled air were $55 \mathrm{l} /$ minute during training and $70 \mathrm{l} /$ minute during races.

Plasma at the beginning and at the end of the study was collected from 11 study subjects and nine controls. The supplementation group had higher baseline concentrations of $\beta$-carotene and $\alpha$-tocopherol than the control group (table $2)$. Individual changes of plasma concentrations of $\beta$-carotene and $\alpha$-tocopherol were used as a marker of compliance. The supplementation group had a significantly higher increase in $\beta$-carotene and $\alpha$-tocopherol than did the control group, as expected (table 2).

Table 3 presents the median and weighted mean regression coefficients after exercise of $\mathrm{FVC}, \mathrm{FEV}_{1}, \mathrm{PEF}$, and MMEF with eight hour mean ozone concentration for the control and supplementation group. Median coefficients were more negative, except for MMEF, for the control group than for the supplementation group, indicating a decrease in lung function at higher ozone concentrations in the control group. After weighting the individual regression coefficients with the inverse of the variance, mean coefficients of $\mathrm{FVC}, \mathrm{FEV}_{1}$, and PEF were more negative than medians in the control group. The MMEF was not associated with ozone. For the supplementation group, none of the lung function variables were associated with ozone concentrations. The weighted mean regression coefficients of FVC imply that a difference in exposure of 100 $\mu \mathrm{g} / \mathrm{m}^{3}$ ozone would decrease FVC by $183 \mathrm{ml}$ in the control group and increase FVC by $25 \mathrm{ml}$ in the vitamin group. The difference between the two groups was significant for FVC, $\mathrm{FEV}_{1}$, and PEF. There was no significant difference between the study groups for MMEF.

The Pearson correlation coefficient for ozone with eight hour mean ambient temperature was 0.93. Conventional adjustment for

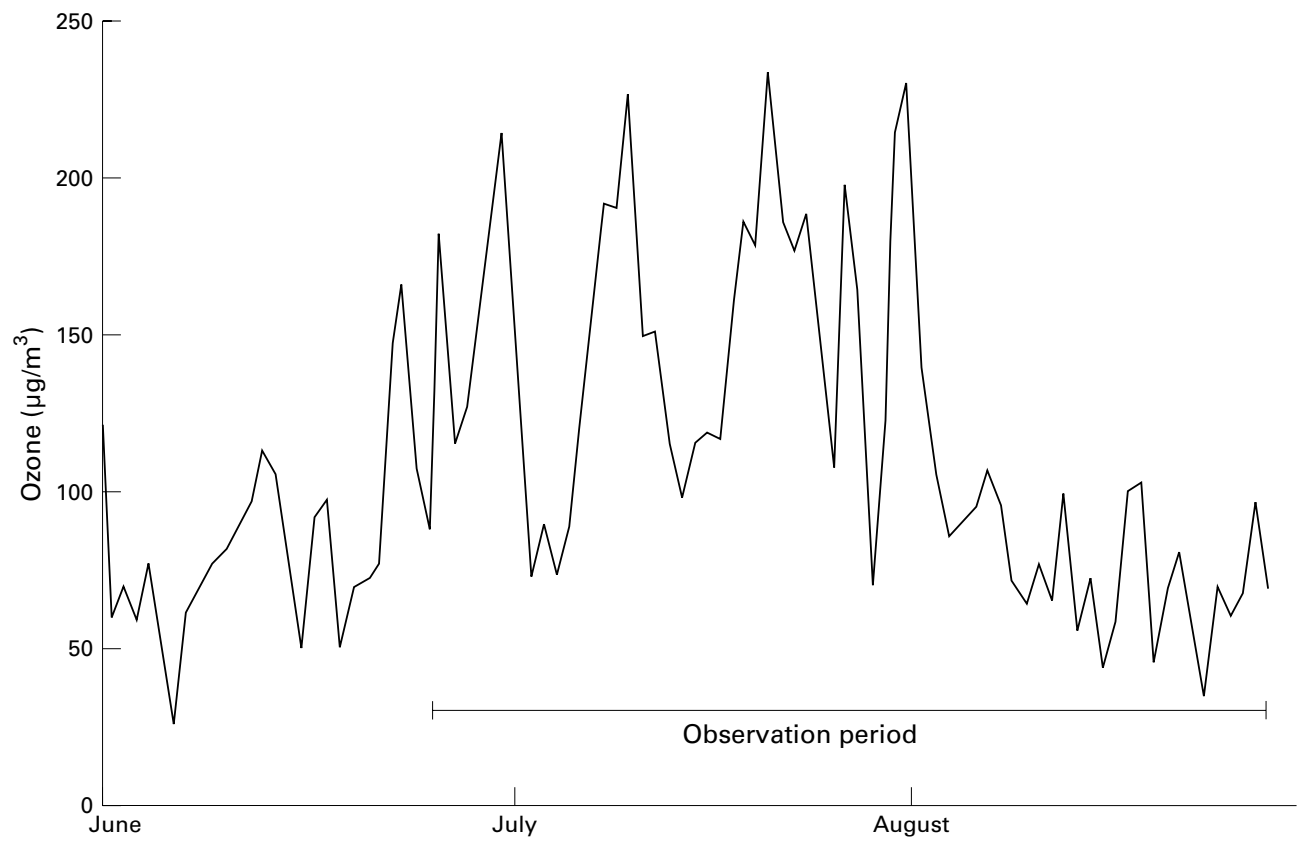

Plot of the one hour maximum ozone concentration per day $\left(\mu \mathrm{g} / \mathrm{m}^{3}\right)$ from 1 fune until 1 September. Observation period was from 28 fune until 1 September 1994. 
Table 3 Lung function variables after exercise with eight hour mean ozone concentration by study group (control and supplementation)

\begin{tabular}{llclrl}
\hline $\begin{array}{l}\text { Lung function } \\
\text { variable }\end{array}$ & $\begin{array}{l}\text { Control }(n=14) \\
\text { median }^{*}\end{array}$ & $\begin{array}{l}\text { Supplementation } \\
(n=12) \text { median }\end{array}$ & $\begin{array}{l}\text { Control } \\
\text { meant (SEM) }\end{array}$ & $\begin{array}{l}\text { Supplementation } \\
\text { meant (SEM) }\end{array}$ & $\begin{array}{l}\text { Treatment effect } \\
\text { difference (95\% CI)t }\end{array}$ \\
\hline FVC & -0.39 & 0.44 & $-1.83(0.49)$ & $0.25(0.24)$ & 2.08 (1.31 to 2.85) \\
FEV $_{1}$ & -0.35 & -0.013 & $-1.86(0.49)$ & $-0.20(0.60)$ & 1.66 (0.62 to 2.70$)$ \\
PEF & -1.54 & 2.42 & $-5.35(2.03)$ & $1.48(3.04)$ & $6.83(3.17$ to 10.49$)$ \\
MMEF & -0.93 & -1.46 & $-0.93(0.94)$ & $-0.51(0.93)$ & $0.42(-1.38$ to 2.22$)$ \\
\hline
\end{tabular}

* Median coefficients in $\mathrm{ml} / \mu \mathrm{g} / \mathrm{m}^{3}$.

† Mean coefficients (SEM) in $\mathrm{ml} / \mu \mathrm{g} / \mathrm{m}^{3}$ for $\mathrm{FVC}$ and $\mathrm{FEV}_{1}$ and in $\mathrm{ml} / \mathrm{s} / \mu \mathrm{g} / \mathrm{m}^{3}$ for PEF and MMEF weighted with inverse of variance; difference $=$ supplementation-control groups.

temperature was problematic because of this high correlation. Restricting the data to lower ambient temperatures was difficult to interpret because of the remaining few observationsthat is, $<40 \%$ of the total observations. Adjustment for $\mathrm{NO}_{2}$ as an independent variable in the model did not change the estimated regression coefficients of ozone on lung function. Adjustment for $\mathrm{PM}_{10}$ also did not change the regression coefficients of ozone on lung function.

\section{Discussion}

The results of this study suggest that antioxidant supplementation might protect against acute ozone effects on lung function (in particular for FVC, $\mathrm{FEV}_{1}$, and PEF).

We also considered an additional regression analysis on all measurements on all subjects. After adjustment for trend, the regression coefficients of $\mathrm{FEV}_{1}\left(\beta=-0.29 \mathrm{ml} / \mu \mathrm{g} / \mathrm{m}^{3}\right.$ in the control group and $\beta=-0.18$ in the vitamin group) and FVC $(\beta=-0.92$ in the control group and $\beta=-0.0014$ in the vitamin group) were comparable with the medians of the regression coefficients (table 3 ). The difference between the control and supplementation group was significant for FVC. The unadjusted regression coefficients for PEF and MMEF were also comparable with the presented medians. So, the results were similar, independent of the method of analysis, with a more negative regression coefficient in the control group than the supplementation group.

Adjustment of ambient temperature as a possible confounder was difficult because of the very high correlation with ozone. Ambient temperature is, however, not such an influential confounder, as indicated by other studies. ${ }^{6} 1415$ Experimental studies showed some ozone effects with very high temperatures $\left(>35^{\circ} \mathrm{C}\right)$ and high ozone concentrations $(>600$ $\left.\mu \mathrm{g} / \mathrm{m}^{3}\right) .{ }^{14}$ Brunekreef and coworkers ${ }^{6}$ also found no temperature effect under ambient conditions with an average temperature of $18^{\circ} \mathrm{C}$.

Adjustment for $\mathrm{PM}_{10}$ did not change the results. Hoek et al ${ }^{16}$ also did not find an effect of low concentrations of $\mathrm{PM}_{10}$ on the relation between ozone and lung function during a summer in The Netherlands. Adjustment for $\mathrm{NO}_{2}$ concentrations did also not change the results. This could be expected as eight hour mean $\mathrm{NO}_{2}$ concentrations were low during that summer with a mean of $23 \mu \mathrm{g} / \mathrm{m}^{3}$ and a range of $4-60 \mu \mathrm{g} / \mathrm{m}^{3}$. Also, $\mathrm{NO}_{2}$ concentrations were not associated with the lung function variables (data not shown).
More subjects with respiratory symptoms and allergies were present in the supplementation group. This suggests that randomisation was not completely successful. However, the results were probably not affected because several other studies indicated that there was no difference in acute effects of ozone between groups with or without respiratory symptoms or allergies. ${ }^{2}{ }^{16}$

Baseline plasma concentrations of $\beta$-carotene and $\alpha$-tocopherol were higher in the supplementation group, which could be explained by three subjects in the supplementation group who used habitual vitamin supplementation at the start of the study. Two of the subjects stopped taking extra supplementation during the study and were randomly assigned to the supplementation group. Excluding all three subjects from analyses resulted in similar regression coefficients for the supplementation group, which implies that results were not affected by these three subjects.

$\alpha$-Tocopherol and $\beta$-carotene in plasma were measured partly to investigate group compliance. The increases in this study were comparable with other supplementation studies. ${ }^{17-19}$ However, comparison can only be rough because duration and amount of supplementation differ between the studies. $\beta$-Carotene and $\alpha$-tocopherol were combined in one capsule. Therefore, if subjects in the supplementation group had a low increase in both antioxidants this would suggest that compliance was not complete. Although the range in individual increases in the supplementation group was large $(9 \%-95 \%$ for $\alpha$-tocopherol; $10 \%-345 \%$ for $\beta$-carotene), possibly due to individual variation in absorption of the antioxidants, there was no subject in this group who had a small increase in both antioxidants.

The control group did not receive a placebo, so the study was not blinded. It is unlikely that this could have affected the results. Both researcher and subject were not aware of the ozone concentrations at the moment of lung function measurements and therefore anticipation of the effect was not possible.

The mechanism by which ozone induces decrements in acute pulmonary function has been under discussion. Inflammatory cells increase within one hour after exposure, but reach a maximum six hours after exposure. This increase does not correlate well with the measured decrements in acute pulmonary function after exposure to ozone..$^{20}$ The current hypothesis for the acute decrements in lung function is a reduction of maximal inspiratory capacity through stimulation of the neural 
receptors in the upper airways. ${ }^{121}$ These receptors are stimulated by cyclo-oxygenase products of arachidonic acid which are released on exposure to ozone. ${ }^{21}$ Vitamins $\mathrm{C}$ and $\mathrm{E}$ have been shown to affect the arachidonic acid metabolism, but the role of antioxidants in this mechanism is not fully understood..$^{2223}$

In summary, this study suggests that one or more of the antioxidants (vitamins $\mathrm{C}, \mathrm{E}$, and $\beta$-carotene) may modulate the acute effects of ozone on lung function. Randomised placebo controlled studies with more subjects and more observations per subject are necessary to increase the precision and confirm the validity of the findings.

We thank all the cyclists and their clubs, WV Ede and RETO, for participating in this study, Bas van Gestel for his assistance in the field work, and Pieter Versloot and Karin den Hartog for assistance in the laboratory work.

1 World Health Organisation. Acute effects on health of smog episodes, Copenhagen: WHO Regional Office for Europe, 1990.

2 Lippmann M. Health effects of ozone. A critical review. fournal of Air Pollution Control Association 1989;39:672-95.

3 Gong $\mathrm{H}$ Jr, Bradley PW, Simmons MS, Tashkin DP. Impaired exercise performance and pulmonary function in elite cyclists during low-level ozone exposure in a hot environment. Am Rev Respir Dis 1986;134:726-33.

4 Avol EL, Linn WS, Venet TG, Shamoo DA, Hackney JD. Avol EL, Linn WS, Venet TG, Shamoo DA, Hackney JD. dant pollution exposure during heavy exercise. fournal of Air Pollution Control Association 1984;34:804-9.

5 Horstman DH, Folinsbee LJ, Ives PJ, Abdul-Salaam S, MacDonell WF. Ozone concentration and pulmonary response relationships for 6.6-hour exposures with five hours of moderate exercise to $0.08,0.10$, and $0.12 \mathrm{ppm}$. Am Rev Respir Dis 1990;142:1158-63.

6 Brunekreef B, Hoek G, Breugelmans O, Leentvaar M. Respiratory effects of low-level photochemical air pollution in amateur cyclists. Am ₹ Respir Crit Care Med 1994;150:9626.

7 Menzel DB. Antioxidant vitamins and prevention of lung disease. Ann N Y Acad Sci 1992;669:141-55.

8 Chatham MD, Eppler JH Jr, Saunder LR, Green D, Kulle TJ. Evaluation of the effects of vitamin $\mathrm{C}$ on ozone induced bronchoconstriction in normal subjects. Ann N Y Acad Sci 1987;498:269-79.

9 Hackney JD, Linn WS, Buckley RD, Jones MP, Wightman LH, Karuza SK. Vitamin E supplementation and respiratory effects of ozone in humans. $\mathcal{F}$ Toxicol Environ Health 1981;7:383-90.

10 Colucci AV. Comparison of the dose-effect relationship between $\mathrm{NO}_{2}$ and other pollutants. In: Schneider T, Grant $\mathrm{LD}$, eds. Air pollution by nitrogen oxides. Amsterdam: Elsevier Science Publishing, 1982;427-40.

11 Quanjer $\mathrm{PhH}$. Standardized lung function testing. Bulletin Européen de Physiopathologie Respiratoire 1983;19:7-86.

12 Johnson LR, Enright PL, Voelker HT, Tashkin DP. Volume spirometers need automated internal temperature sensors. Am $\mathcal{F}$ Respir Crit Care Med 1994;150:1575-80.

13 SAS. SAS/STAT user's guide. Cary: SAS Institute, 1996.

14 Folinsbee LJ, Horvath SM, Raven PB, Bedi JF, Morton AR, Drinkwater BL, et al. Influence of exercise and heat stress on pulmonary function during ozone exposure. $f \mathrm{Appl}$ Physiol 1977;43:409-13.

15 Gibbons SI, Adams WC. Combined effects of ozone exposure and ambient heat on exercising females. 7 Appl Physiol 1984;57:450-6.

16 Hoek G, Fisher P, Brunekreef B, Lebret E, Hofschreuder P, Mennen MG. Acute effects of ambient ozone on pulmonary function of children in the Netherlands. Am Rev Respir Dis 1993;147:111-7.

17 Kardinaal AFM, van 't Veer P, Brants HAM, van den Berg $\mathrm{H}$, van Schoonhoven J, Hermus RJJ. Relations between antioxidant vitamins in adipose tissue, plasma, and diet. Am F Epidemiol 1995;141:440-50.

18 Salonen JT, Salonen R, Seppänen K, et al. Effects of antioxidant supplementation on platelet function: a randomized pair-matched, placebo-controlled, double-blind trial in pair-matched, placebo-controlled, double-blind 1rial in men with

19 London RS, Sundaram GS, Manimekalai S, Murphy L, Reynolds MA, Goldstein P. Serum $\alpha$-tocopherol levels in relation to serum lipids and lipoproteins after oral administration of vitamin E. In: Prasad, ed. Vitamins, nutrition and cancer. Basel: Karger, 1984;159-65.

20 Schelegle ES, Siefkin AD, McDonald RJ. Time course of ozone-induced neutrophilia in normal humans. Am Rev Respir Dis 1991;143:1353-8.

21 Hazucha MJ, Bates DV, Bromberg PA. Mechanism of action of ozone on the human lung. $\mathcal{F}$ Appl Physiol 1989;67:153541 .

22 Ogilvy CS, DuBois AB, Douglas JS. Effects of ascorbic acid and indomethacin on the airways of healthy male subjects with and without induced bronchoconstriction. F Allergy Clin Immunol 1981;67:363-9.

23 Mohsenin V, DuBois AB, Douglas JS. Effect of ascorbic acid on response to methacholine challenge in asthmatic subjects. Am Rev Respir Dis 1983;127:143-7. 